\title{
MULHERES E DESPORTO: A (SUB)REPRESENTAÇÃO DAS MULHERES NA DIREÇÃO DAS FEDERAÇÕES OLÍMPICAS PORTUGUESAS
}

\author{
Maria José Carvalho \\ Universidade do Porto, Porto, Portugal \\ Carla Pinto \\ Universidade do Porto, Porto, Portugal \\ Paula Botelho Gomes \\ Universidade Lusófona do Porto, Porto, Portugal
}

\begin{abstract}
Resumo
Atualmente existe uma vasta legislação nacional e internacional defensora dos direitos humanos, contudo persistem desigualdades entre homens e mulheres. Apesar da maior participação das mulheres no desporto, verifica-se a sua sub-representação em cargos de liderança e decisão. Daí o nosso propósito em analisar a representatividade das mulheres nestes cargos nas federações olímpicas portuguesas. Metodologicamente, as mulheres com cargos elevados na direção daquelas federações constituem a amostra do estudo, às quais foram realizadas entrevistas semidiretivas. As principais conclusões indicam desigualdades de oportunidades no acesso aos referenciados cargos devido a: questões culturais, estereótipos do género, cultura organizacional e gestão do tempo.
\end{abstract}

Palavras-chave: Feminismo. Liderança. Organizações sem Fins Lucrativos.

\section{Introdução}

A problemática da igualdade de oportunidades entre homens e mulheres não é uma temática recente, nem de somenos importância ou matéria irrelevante para a humanidade. Sempre existiram desigualdades sociais, económicas e humanas.

Existe um longo percurso histórico-evolutivo da problemática da igualdade, enquanto ideal de consciência do ocidente (CASTRO; CARVALHO, 1998).

Nos últimos anos, as questões de género e igualdade de género foram trazidas para a esfera pública juntamente com o reconhecimento da importância da equidade no processo de desenvolvimento sustentável. "É precisamente na década de noventa que a perceção da situação da mulher e dos direitos de igualdade e oportunidades de género 
inserida numa perspetiva de direitos humanos é abertamente assumida" (INSTITUTO NACIONAL DE ESTATÍSTICA, 2002, p.11).

É extremamente importante garantir os direitos humanos e a justiça social, tanto para homens como para mulheres e cada vez mais o mainstreaming de género é reconhecido como fundamental nas diversas áreas de desenvolvimento e "pode revelar a necessidade de mudanças nos objetivos, estratégias e ações para garantir que ambos, mulheres e homens, possam influenciar, participar e beneficiar dos processos de desenvolvimento. Isto pode levar a mudanças nas organizações - estruturas, procedimentos e culturas - para criar um ambiente organizacional que são propícias à promoção da igualdade de género" (UNITED NATIONS, 2002, p. 6).

Apesar dos grandes avanços, ainda hoje vivemos numa sociedade patriarcal, na qual as discriminações das mulheres em relação aos homens se verificam a vários níveis, entre os quais destacamos, os baixos salários, menores oportunidades para aceder a cargos de poder, maiores jornadas de trabalho (profissional e privado) e em caso de despedimento as mulheres são as primeiras a perder os seus postos de trabalho.

O combate às inegáveis desigualdades de género em todas as esferas da vida (entre outras, na política, no desporto, no mercado de trabalho, na vida pública e privada), não se compadece apenas com bonitas palavras registadas nas várias declarações, resoluções, recomendações, planos e legislação, produzidas por várias instituições internacionais e nacionais. É fundamental e imprescindível que as medidas que constam nestes documentos de referência sejam efetivamente promovidas, implementadas e supervisionadas por todos os Estados de direito, bem como respeitadas e cumpridas por todos aqueles que pretendem viver uma efetiva democracia.

A igualdade de oportunidades e a participação equilibrada de homens e mulheres no espaço público e privado é um fator essencial para o desenvolvimento de uma sociedade e é uma garantia da democracia (CORBACHO, 2005 apud ASTELARRA, 2005).

É facilmente constatável que a maioria das mulheres tem o seu tempo repartido em inúmeras atividades, entre as quais as tarefas domésticas, os cuidados prestados aos filhos, o trabalho profissional e a participação cívica, sendo que o tempo disponibilizado para concretizar todas estas atividades é subestimado a nível social e económico (PERISTA; MAXIMIANO; FREITAS, 2000). 
Um estudo realizado em Portugal concluiu que existe uma sobrecarga feminina materializada predominantemente na esfera privada, existindo desta forma assimetrias gritantes que diminuem quando passamos para a esfera pública (TORRES et al., 2000). Desta forma, parece-nos inevitável que as desigualdades de género existentes na vida privada podem ter repercussões perniciosas numa sociedade. Por isso mesmo, questões de igualdade de género não devem ser desvalorizadas, tanto na vida privada como na vida pública.

\section{Mulheres e desporto}

No mundo do desporto a situação não é diferente do que se verifica nos outros domínios da sociedade.

Ao reportarmo-nos à história do desporto, esta revela que foi e ainda continua a ser um espaço associado a uma identidade masculina e que ao longo dos tempos a mulher foi conquistando o seu espaço no mundo desportivo, ao mesmo tempo que o seu valor foi reconhecido. Segundo Cruz, Silva e Botelho-Gomes. (2006, p. 55) "as mulheres ao reivindicarem iguais direitos e oportunidades no desporto, ao transporem fronteiras que lhes foram impostas, tornaram-se guerreiras".

Um olhar mais atento sobre a realidade portuguesa, também revela a existência de desigualdades de género entre homens e mulheres, principalmente no sector desportivo. O desporto "é um modelo de realidade social, ainda, do domínio masculino" (SIMÕES, 2003, p.1). São vários os exemplos que podemos enumerar, a nível dos prémios de competição; dos índices de prática desportiva; da utilização das instalações e do espaço concedido; do tratamento nos meios de comunicação social, entre outros. Mas, mais flagrante ainda, é a fraca representatividade das mulheres nas esferas de poder e, mais concretamente, nos lugares de decisão no desporto.

Um estudo realizado em Portugal, sobre "A mulher nas instâncias federativas do desporto" (ALMEIDA, 2000), revelou que existia uma sub-representação das mulheres no dirigismo desportivo (110 mulheres contra 957 homens) e à medida que se subia na hierarquia dos órgãos e dos cargos, a percentagem diminuía.

A sub-representação das mulheres no dirigismo desportivo permanece, por exemplo, ao nível das federações olímpicas portuguesas. Através dos dados relativos aos órgãos sociais de cada federação, re- 
colhidos em 2009, apenas existem 16\% de mulheres nos órgãos sociais nestas instâncias entre os 824 membros que os compõem.

Podemos ainda acrescentar que no cargo de direção das federações olímpicas portuguesas a taxa de feminização é de 13\% (em 228 membros, 29 são mulheres), verificando-se que à medida que subimos na hierarquia das organizações, a sub-representação das mulheres aumenta. Segundo Pinheiro (1998, p. 24),

a pequena representatividade feminina nestas áreas constitui um indício de que as barreiras à participação feminina no desporto ainda não desapareceram na totalidade, principalmente, de que o desporto ainda está associado a uma imagem de área reservada masculina.

Apesar da legislação existente no sentido de aumentar o acesso das mulheres aos cargos de decisão, dos esforços realizados por parte de organizações internacionais e nacionais e do aumento das qualificações profissionais das mulheres, estas continuam a ser uma minoria nos postos de decisão e na gestão de topo.

A resposta a esta indignação parece estar nas barreiras (in)visíveis e estereótipos em função do sexo (os constrangimentos familiares e a estrutura "político-cultural" das organizações, entre outros) que prevalecem na nossa sociedade. Carvalho $(2000$, p.1) afirma que "existe uma correlação, implícita e tomada como universal, entre os homens, o poder e a autoridade no seio das organizações".

Ainda hoje, nas organizações desportivas, o acesso aos cargos de decisão é feito, principalmente, através de convite direto, e sendo estas organizações conservadoras e dominadas por homens, reduz-se ainda mais as probabilidades das mulheres serem escolhidas. Costa (2007) considera que para aceder a um cargo de gestão ou administração, os candidatos/as têm de corresponder ao perfil exigido. Mas para estabelecer esse perfil é importante definir critérios para que este esteja adequado às funções inerentes ao cargo a desempenhar.

São muitos os desafios que as mulheres enfrentam quando se trata de aceder a cargos de liderança. A falta de confiança para concorrer a eleições, a falta de apoio por parte de quem está dentro da instituição e a falta de experiência são, segundo Talbot (2001), alguns exemplos desses desafios. 
A conciliação entre a vida pública e a privada é outra barreira que as mulheres têm de transpor, principalmente no que se refere à gestão do tempo. Atualmente tanto as mulheres casadas e com filhos, como as solteiras ou divorciadas sentem dificuldades em conciliar estas "duas vidas", no entanto, a situação é pior no primeiro caso. No caso das casadas as dificuldades estão associadas às responsabilidades familiares enquanto que as "solteiras" estão relacionadas com a sua vida profissional e projetos pessoais.

A entrada da mulher no mercado de trabalho não se fez acompanhar das reestruturações necessárias na sociedade (creches, pessoal de serviço), o que sobrecarrega a mulher com a dupla jornada de trabalho, pois o homem, via regra, não dispõe de seu tempo para as crianças e para o lar, dificultando para a maioria das mulheres a competição pelo poder (FREITAS, 2003, p. 50).

Esta autora remete-nos para uma reflexão bastante interessante. O que é que foi feito até hoje para dar resposta às questões relacionadas com as desigualdades de género em Portugal, a nível geral e no desporto em particular? A resposta depende do prisma de análise da questão, isto é, depende se estamos a aludir à existência de documentos de referência como por exemplo, legislação, planos ou declarações, ou se estamos a considerar uma efetiva intervenção por parte daqueles que detêm o poder para o fazer. Para o primeiro caso, teremos de considerar que já foi feito algo de substancial nesse sentido, mas no que diz respeito a ações específicas, diremos que não é visível qualquer intervenção para dar resposta à questão colocada no domínio do desporto.

A nível legislativo e começando pela lei mais importante do nosso País, a Constituição da República Portuguesa, esta estatui que nenhum cidadão pode ser prejudicado, ou privado de qualquer direito em razão do sexo (artigo $13 .^{\circ},{ }^{\circ}{ }^{\circ}$ 2). Preceitua ainda que a todos são reconhecidos os direitos à proteção legal contra quaisquer formas de discriminação (artigo 26. ${ }^{\circ}$, n. ${ }^{\circ}$ 1). Para assegurar o trabalho, incumbe ao Estado promover a igualdade de oportunidades na escolha da profissão ou género de trabalho e condições para que não seja vedado ou limitado, em função do sexo, o acesso a quaisquer cargos, trabalho ou categorias profissionais (n. ${ }^{\circ} 2$, alínea $b$ ), do artigo $\left.58 .^{\circ}\right)$. De forma explícita consagra o direito a todos ao desporto (artigo $79 .^{\circ}$, n. $^{\circ} 1$ ). Em 
consonância a Lei de Bases da Atividade Física e do Desporto estatui explicitamente que a atividade física e o desporto devem contribuir para a promoção de uma situação equilibrada e não discriminatória entre homens e mulheres (artigo $2 .^{\circ}, \mathrm{n}^{\mathrm{o}} 2$ ).

Em suma, podemos afirmar que existem "alicerces legais" aceitáveis para combater as desigualdades de género e as discriminações entre homens e mulheres. No entanto, os estereótipos do género permanecem como barreiras fortes à concretização de uma efetiva igualdade nas várias esferas da vida, inclusive no desporto.

A sub-representação de mulheres nos cargos de liderança e de decisão (ALMEIDA, 2000) é a prova desta amarga realidade que necessita de todos para ser alterada e para se atingir uma autêntica sociedade democrática.

Com intuito de contribuir para o conhecimento real sobre a representação das mulheres nas organizações desportivas, e uma vez que existem poucos trabalhos neste domínio, propusemo-nos realizar um estudo neste âmbito com a metodologia que a seguir descrevemos.

\section{Metodologia}

Do universo das federações desportivas portuguesas ( 74 federações no total) decidimos circunscrever o nosso estudo às federações olímpicas portuguesas com Estatuto de Utilidade Pública Desportiva (EUPD) e que são 29. Ulteriormente indagou-se qual a composição dos órgãos sociais relativamente ao sexo para saber qual a taxa de feminização existente nestas federações.

O grupo a estudar foi assim definido: mulheres que desempenhavam cargos de presidente, vice-presidente ou de adjunta de presidente em federações olímpicas portuguesas com Estatuto de Utilidade Pública Desportiva.

Destas decisões resultou uma amostra oriunda de 8 Federações Basebol/Softebol, Ginástica, Hóquei, de Natação, Remo, Taekwondo, Ténis e Triatlo - constituída por 13 mulheres, sendo que 1 exerce o cargo de presidente, 1 de adjunta e 11 de vice-presidente.

A entrevista foi o processo aplicado para a recolha de dados. Foram realizadas entrevistas semi-directivas a todos os elementos da amostra após consentimento informado. Para as entrevistas foi utilizado um guião, previamente testado e validado por duas especialistas (QUIVY; CAMPENHOUDT, 2005), com as grandes linhas dos temas a explorar: 
acesso ao cargo/recrutamento; conciliação vida pública/vida privada; barreiras e estereótipos associados ao cargo.

Cumpriram-se os aspetos formais e éticos devidos: a apresentação da entrevistadora e do tema geral de investigação; o informar da confidencialidade da informação em todo o processo, tendo sido ainda pedida autorização para registo áudio. Os registos áudio foram integralmente transcritos em formato digital. Para o tratamento dos dados resultantes das entrevistas recorreu-se à análise de conteúdo (BARDIN, 2008), tendo em conta a revisão da literatura e os temas daí decorrentes.

\section{Apresentação e discussão dos resultados}

A partir das decisões metodológicas adotadas constatou-se no presente estudo que as mulheres estão sub-representadas nas federações olímpicas portuguesas ( $16 \%$ dos membros são mulheres), e em particular no cargo de direção, onde apenas existem 29 mulheres. Do que foi possível apurar, existe 1 mulher presidente; 11 vice-presidentes; 1 adjunta de presidente; 6 vogais; 6 suplentes e 1 tesoureira.

Das 29 federações olímpicas apenas 8 têm mulheres a ocupar o cargo de presidente, adjunta de presidente e vice-presidente, são elas: a Federação Portuguesa de Basebol/Softebol; Federação de Ginástica de Portugal; Federação Portuguesa de Hóquei; Federação Portuguesa de Natação; Federação Portuguesa de Remo; Federação Portuguesa de Taekwondo; Federação Portuguesa de Ténis e a Federação de Triatlo de Portugal.

Passamos de seguida à apresentação e discussão dos resultados referentes aos temas explorados nas entrevistas.

\section{Recrutamento}

As mulheres do nosso estudo, de uma forma geral, foram convidadas para integrar a respetiva direção federativa. Apenas uma teve a iniciativa de se propor à sua eleição. Segundo Talbot (2001) a falta de confiança para concorrer a eleições e a falta de apoios por parte de quem está dentro da organização, são alguns desafios que as mulheres enfrentam quando tentam atingir cargos de liderança. $\mathrm{O}$ estudo realizado na Alemanha (Pfister e Radtke, 2007) comprova isso mesmo, as mulheres, apesar de planearem as suas carreiras, têm a tendência a es- 
perar que alguém as encoraje, principalmente um dirigente desportivo, a candidatar-se aos mais altos cargos.

Os resultados obtidos vão ao encontro do estudo realizado por Chimot (2004), em que a maioria das mulheres foram sugeridas por outra pessoa, bem como ao do estudo de Gomes (2008), no qual se concluiu que as presidentes das federações desportivas acederam ao cargo através de eleição, no entanto, as gestoras públicas que acederam aos cargos da Secretaria Nacional do Desporto de Alto Rendimento, no Ministério do Desporto foi através de convite de amigos ou de companheiros.

Salientamos que não é possível afirmar quais são as federações olímpicas que tinham critérios definidos para o perfil exigido para o cargo, uma vez que as entrevistadas se referiram ao seu caso específico e na mesma federação, umas entrevistadas foram escolhidas segundo critérios definidos e outras não.

Assim constatamos que apenas cinco das entrevistadas (5/13) foram escolhidas para os cargos tendo em conta critérios definidos pela respetiva federação, sendo a formação académica o critério mais utilizado pelas federações. No entanto, existiram outros critérios: o facto de ser mulher; o passado desportivo; a ligação, de forma indireta, com a modalidade em questão, bem como novas perspetivas e ideias.

Isto demonstra que as federações olímpicas portuguesas ainda funcionam como "empresas familiares" em que os conhecimentos pessoais (convite direto) são o critério mais utilizado para a escolha das pessoas para os cargos. Tal também ficou evidente noutros estudos, nomeadamente no estudo realizado por Gomes (2008).

Segundo o nosso estudo, a forma como as pessoas são escolhidas para os cargos não promove a igualdade de oportunidades entre homens e mulheres, antes pelo contrário, leva a que situações de discriminação e de desigualdade de género possam ocorrer com mais frequência. Por um lado, o facto de não existir um perfil definido e se convidar as pessoas por serem conhecidas, dificulta o acesso de novas candidatas e as desvantagens para as mulheres aumentam, uma vez que o desporto é um mundo maioritariamente masculino. Por outro lado, segundo Santos (2003 apud COSTA, 2007), a inexistência de um perfil definido do/a candidato/a para o cargo, pode originar uma escolha errada para o cargo em questão, porque os candidatos/as podem ter características adequadas para um cargo mas não serem as necessárias ou as mais adequadas para ocupar esse cargo específico. 
Por tudo o que já foi mencionado e tendo em atenção a Declaração de Brighton, na qual está explícito que os responsáveis pelas organizações desportivas devem aumentar o número de mulheres nos seus cargos, principalmente nos de direção, dando uma especial atenção ao recrutamento (princípio 6 - direção do desporto), consideramos que as federações olímpicas portuguesas têm que rever a "forma" como escolhem os seus membros para os cargos para efetivamente promoverem a equidade entre mulheres e homens.

\section{Conciliação entre a vida pública e a privada}

Em termos de conciliação da vida pública com a vida privada, a maioria das entrevistadas (7/13) sente algumas dificuldades nesse âmbito, contudo conseguem superá-las (as casadas relativamente aos filhos e as solteiras ou divorciadas em relação à profissão ou projetos pessoais). As principais dificuldades para as dirigentes casadas e com filhos são a gestão do tempo, o horário das reuniões (principalmente por serem ao final da tarde), as provas ao fim de semana e a disponibilidade. Para as entrevistadas solteiras ou divorciadas as dificuldades estão relacionadas com a gestão do tempo. Como se pode verificar nos discursos de algumas entrevistadas: "[...] As maiores dificuldades... são em termos de gestão de tempo [...] e tenho as filhas relativamente pequeninas $[\ldots]$ nunca digo que não consigo resolver a situação... mas... só com uma grande ajuda e essencialmente... do meu marido, [...] tenho a sorte de ter uma sogra que me ajuda, é ela o meu suporte em termos de gerir a minha vida pessoal em termos das minhas filhas" (Mb1); “[...] apesar de não ter filhos tenho naturalmente uma vida familiar não é (...) tenta-se, consegue-se. [...] claro que sinto dificuldades [...] pronto passar dias fora" (Mb2); "Sinto. As reuniões ao fim do dia por exemplo [...] os fins da tarde são complicados com a família, com as crianças [...] não é fácil, mas também faz-se" (Mc1); “[...] acabo por ter mais dificuldades em conciliar o meu cargo aqui na direção da federação com a minha vida profissional [...] incompatibilidades de horários [...] mas vou sempre tentando... conciliar" (Md1).

As restantes entrevistadas não sentem dificuldades em conciliar a sua vida pública com a privada porque: 1) a maioria é solteira ou divorciada, por isso organizam o seu tempo em função delas próprias ou então aquilo que fazem é a sua vida e 2) as que são casadas têm a vida bem organizada ou têm uma família que as apoia (o marido está inse- 
rido no meio desportivo e os filhos já estão habituados a ser independentes).

O suporte familiar revela-se fundamental e imprescindível para que a conciliação da vida privada e pública seja possível, principalmente para as entrevistadas que são casadas e que têm filhos.

Os resultados obtidos confirmam o que outros estudos realizados neste âmbito também constataram. No estudo de Gomes (2008) realizado no Brasil, as gestoras, embora sejam uma minoria, não conseguem inserir-se no "primeiro escalão" do desporto brasileiro porque não têm espaço que lhes permita exercer as funções de mãe, esposa e dona de casa. A maioria das mulheres consegue conciliar a sua vida privada com a vida pública porque, ou são solteiras ou então, as casadas contam com a participação ativa por parte dos maridos nas tarefas domésticas e nos cuidados com os filhos ou então, trabalham com os maridos e os filhos já são adultos.

O estudo realizado em Espanha, por Fernández e Ventura (2005), também refere que a nível dos postos diretivos na Europa, a conciliação do trabalho e as restantes atividades quotidianas são dificuldades que as mulheres têm no que diz respeito à sua inclusão nas organizações desportivas.

Segundo o estudo do Institute of Sport and Leisure Policy (2004) algumas mulheres que trabalham a tempo inteiro e têm responsabilidades familiares, encontram-se mais pressionadas, pois os papéis tradicionais de género e os padrões do trabalho doméstico estão presentes em suas casas. Apesar de contarem com o apoio da família e dos companheiros, sacrificam, por vezes, as suas relações pessoais.

No estudo realizado na Alemanha (PFISTER; RADTKE, 2007) também se concluiu que é mais difícil para as mulheres do que para os homens atingir o equilíbrio entre o trabalho e a vida pessoal, uma vez que cabe sobretudo às mulheres a tarefa de resolver os conflitos estruturais entre ganhar dinheiro, cuidar dos filhos e ter uma família e outras atividades.

No estudo realizado em Lisboa (ALVES; BALTAZAR; OLIVEIRA, 1998) as dirigentes sentem dificuldades em conciliar o trabalho realizado na coletividade e a vida doméstica e familiar, ao ponto de considerarem que dedicam pouco tempo à família e à casa.

Consideramos que as dificuldades em conciliar a vida pública com a vida privada continuam a persistir, sejam as mulheres casadas ou não, e o fator tempo constitui a maior limitação às necessidades ou in- 
teresses das mulheres. A maioria das mulheres tem que diariamente fazer muita "ginástica mental" para gerir o seu tempo de acordo com todas as atividades em que está envolvida, sendo mais complicado para as mulheres que "têm filhos pequenos, empregadas e que continuam a realizar a maior parte do trabalho doméstico" (ALVES; BALTAZAR; OLIVEIRA, 1998, p. 149). A ajuda familiar é o grande suporte da maioria das mulheres, sem essa colaboração era quase impossível as mulheres realizarem os seus projetos ou dedicarem-se se a outros interesses.

As dificuldades em conciliar a vida pública com a privada são referidas em várias resoluções, recomendações e declarações, nacionais e internacionais, como sendo uma das principais barreiras à promoção da igualdade de oportunidades entre homens e mulheres. Em todos os Planos Nacionais para a Igualdade de Género são referidas medidas para transpor esta barreira. É caso para perguntar, onde e como é que estas medidas estão a ser aplicadas e cumpridas, designadamente no âmbito desportivo?

\section{Barreiras e estereótipos}

De acordo com os resultados obtidos, é inquestionável que as oportunidades de acesso aos cargos de tomada de decisão não são iguais entre homens e mulheres no âmbito desportivo. No entanto, algumas entrevistadas (4/13) consideram que as desigualdades são maiores no âmbito geral do que no desporto, apenas uma considera que esta situação se verifica mais no desporto e as restantes não fizeram este tipo de análise. Segundo a revisão bibliográfica, as barreiras e os estereótipos que estão na base das desigualdades de género estão mais vincadas no desporto do que nas restantes esferas da vida, mas o nosso estudo não nos permitiu verificar em que âmbito as desigualdades são mais acentuadas porque apenas cinco entrevistadas se referiram a este aspeto específico.

No âmbito geral e na opinião das entrevistadas, as questões culturais são as principais razões para a existência destas desigualdades, designadamente: as responsabilidades familiares (incluindo o cuidar dos filhos) atribuídas às mulheres; a menor dedicação dos homens à família; os estereótipos associados às mulheres; as barreiras de costumes, de civilização e de hábito; o menor reconhecimento das competências das mulheres (estas têm de provar que são tão boas ou 
melhores que os homens para terem acesso aos cargos) e tradicionalmente o fato destes cargos ainda estarem muito associados aos homens. "[...] Se um homem se dedicasse com a mesma intensidade à vida familiar como uma mulher, se calhar as oportunidades seriam as mesmas (Ma1)";. "[...] em organizações para onde eu trabalho [...] nem sequer é aceite o facto de haver uma mulher nos órgãos sociais... $[\ldots]$ ainda não existem, porque eles consideram que as mulheres [...] não são boas profissionais para órgãos de decisão... nem pensar" (Mb1).

Em relação ao desporto, para além das questões culturais, a estrutura organizacional do desporto também é outra das razões para a existência de desigualdades de género no acesso aos cargos de decisão: a existência de grandes jogos políticos e de sedução (e as mulheres terem dificuldades em fazer esses jogos); os dirigentes do topo das organizações têm uma grande rede de contatos estabelecida, não sendo a competência um dos critérios para esses contatos; o desporto é um meio maioritariamente masculino e o acesso aos cargos ainda é feito sobretudo através de convite direto (convidando-se geralmente o homem conhecido, companheiro e colega).

Julgamos que o discurso destas entrevistadas resume bem o que foi mencionado anteriormente. "[...] infelizmente ... o desporto regese por regras e por estruturas às vezes estranhas $[. .$.$] faz com que às$ vezes as competências não sejam suficientes" (Ma1); "Acho que a mulher tem que provar ... que é tão boa ou melhor que o homem em termos técnicos para conseguir ascender a esses cargos, ainda há um certo machismo $[\ldots]$ muitos desses cargos até são por convite direto e quando há que convidar alguém, geralmente convida-se até o homem conhecido, companheiro, colega e muitas vezes esquecem-se das mulheres" (Mh2).

Os resultados do nosso estudo vão ao encontro do que as várias ações e recomendações internacionais e nacionais vêm chamando à atenção, o facto de haver desigualdades de oportunidades baseadas em estereótipos e a existência de barreiras culturais que impedem a equidade de género.

A dificuldade de conciliar as responsabilidades familiares com as restantes atividades do quotidiano, a posição que o homem ocupa no mundo do trabalho, bem como a falta de oportunidades para as mulheres acederem aos cargos, são a principais barreiras também aludi- 
das no estudo de Fernández e Ventura (2005), verificando-se o mesmo no nosso estudo.

O estudo realizado na Alemanha (PFISTER; RADTKE, 2007) também chegou às mesmas conclusões, ou seja, que as barreiras não são causadas apenas por restrições de género, mas também por questões como a cultura organizacional desportiva; a dificuldade de conciliação entre a vida pública e privada, principalmente a falta de condições e de apoio dentro e fora de casa e a menor disponibilidade das mulheres para desempenhar cargos de decisão.

Os estudos realizados entre 2003 e 2005 em países como a Finlândia, Hungria, Itália, Espanha e Reino Unido (ASTELARRA, 2005) mostram que através de medidas específicas como a revisão dos sistemas de contratação e de promoção, a formulação de políticas favoráveis à família, a evolução da cultura organizacional e a formação, é possível alcançar a igualdade de oportunidades, promovendo a participação das mulheres e reforçando a sua presença nos níveis hierárquicos mais elevados.

\section{Conclusões}

1. As mulheres estão sub-representadas nas federações olímpicas portuguesas (16\% dos membros são mulheres), e em particular no cargo de direção, onde apenas existem 29 mulheres.

2. Das 29 federações olímpicas, objeto do presente estudo, apenas 8 têm mulheres a ocupar o cargo de presidente, adjunta de presidente e vice-presidente.

3. 92,3\% das mulheres acederam ao cargo através de convite, apenas uma se candidatou ao cargo que desempenha atualmente na federação. 4. Apenas $38,4 \%$ das entrevistadas foram convidadas com base num critério (todas elas de federações diferentes), dos quais destacamos: a área de formação; o passado desportivo e a necessidade de ter mulheres na federação. As restantes entrevistadas mencionaram as razões que consideram ter estado na origem do convite, nomeadamente, o trabalho desenvolvido; a experiência; o empreendorismo; a persistência; a capacidade de trabalho; o passado desportivo como dirigentes; o espírito de iniciativa; o gosto pela modalidade; a confiança; a credibilidade e o conhecimento na área.

5. 53,8\% das entrevistadas sentem dificuldades em conciliar a sua vida pública e com a privada, mas conseguem ultrapassá-las, embora não seja fácil. 
A gestão do tempo e a reduzida disponibilidade são as principais razões mencionadas, principalmente para as entrevistadas que são casadas e que têm filhos. No caso das mulheres solteiras ou divorciadas, as dificuldades são as mesmas mas a nível da conciliação da vida profissional e/ou projetos pessoais e o cargo na federação.

Embora contem com o imprescindível apoio da família, não é fácil gerir o tempo em função de todas as atividades em que estão envolvidas no dia-a-dia, principalmente para as que são casadas.

As restantes entrevistadas não têm dificuldades em conciliar a sua vida privada com a vida pública, porque não têm as tradicionais responsabilidades familiares (organizando o seu tempo em função delas próprias) ou porque a família já está habituada e inclusive o marido também está integrado no meio desportivo.

6. Todas as entrevistadas consideram que existem desigualdades de oportunidades no acesso aos mais altos cargos de decisão entre homens e mulheres, quer seja no âmbito geral ou no desporto em particular. No entanto, prevalece a ideia de que esta situação se verifica mais no âmbito geral do que no desporto. Isto porque no desporto, a base inicial é bastante alargada, favorecendo a construção de uma carreira neste âmbito, e por outro lado, se as mulheres forem profissionais, tiverem ajuda da família e não quiserem cargos de destaque, os homens não oferecem resistência e elas chegam onde os homens chegam.

As questões culturais; os estereótipos do género e a cultura organizacional são as principais razões para ainda persistirem as desigualdades de género a nível geral e no desporto em particular.

\title{
WOMEN, SPORT: WOMEN (SUB)REPRESENTATION IN DIRECTIVE
} BOARDS OF OLYMPIC PORTUGUESE FEDERATIONS

\begin{abstract}
In a democracy such as one as we live in, where there is a vast national and international legislation which aims to defend human rights, we continue to witness gender inequality between men and women. Currently, although women participation in sport, they are still under-represented, mainly in the leadership and decision positions. Therefore we wanted to examine women representation in leadership and decision positions on the Portuguese Olympic Federations. Women with high positions in the direction of these federations constitute the sample of the study. The information has been collected through semi-directive interviews. The main results indicate inequality of opportunity in access to positions of reference due to cultural
\end{abstract}


issues, stereotypes of gender, organizational culture and time management.

Keywords: Feminism. Leadership. Nonprofit Organizations.

\section{MUJERES, DEPORTE: (SUB) REPRESENTACIÓN DE LAS MUJERES EN LA DIRECCIÓN DE LAS FEDERACIONES OLÍMPICAS PORTUGUESAS}

\section{Resumen}

Actualmente hay una amplia legislación defensora de derechos humanos, nacional e internacional, sin embargo, persisten desigualdades de género. A pesar de la creciente participación de las mujeres en el deporte, es escasa su representación en posiciones de liderazgo y toma de decisiones. De ahí nuestro propósito de analizar la representatividad de las mujeres en estas posiciones en las federaciones olímpicas portuguesas. Metodológicamente, las mujeres con altos cargos en la dirección de esas asociaciones constituyen la muestra del estudio. La información ha sido colectada a través de entrevistas semi-directivas. Los principales resultados indican la desigualdad de oportunidades en el acceso a posiciones de referencia debido a: cuestiones culturales, los estereotipos de género, cultura organizacional y gestión del tiempo.

Palabras clave: Feminismo. Liderazgo. Organizaciones sin Fines de Lucro.

\section{Referências}

ALMEIDA, C. A mulher nas instâncias federativas do desporto. Revista Desporto, Lisboa, v. 3, p. 6-11, 2000.

ALVES, C.; BALTAZAR, S.; OLIVEIRA, V. Mulheres Dirigentes em Lisboa. In: CONGRESSO A MULHER E O DESPORTO, 1998, Lisboa. Anais... Lisboa: Câmara Municipal de Lisboa/Pelouro do Desporto, 1998. p. 149-157.

ASTELARRA, J. Participación de mujeres y hombres en la toma de decisiones: Análisis de cinco organizaciones europeas, Diciembre 2003-Febrero 2005. Barcelona: Institut d'Edicions de la Diputación de Barcelona, 2005. Disponível em: <http://www.mujerydeporte.org/documentos/docs/Participación\%20de\%20mujeres\%20y\%20hombres_2005.pdf>. Acesso em 25 fev. 2009.

BARDIN, L. Análise de Conteúdo. Lisboa: Edições 70, 2008.

CARVALHO, T. A participação das mulheres na gestão: o caso particular da Gestão de Recursos Humanos. In: CONGRESSO PORTUGUÊS DE SOCIOLOGIA, 4., 2000, Coimbra. Atas... Coimbra: Universidade de Coimbra, $2000 . \quad$ Disponível em: 
$<$ http://www.aps.pt/cms/docs_prv/docs/DPR462dd233668c4_1.PDF>. Acesso em 12 jan. 2009.

CASTRO, P.; CARVALHO, M. J. A Primeira Igualdade é a Justiça: Declaração de Brighton. In: CONGRESSO A MULHER E O DESPORTO, 1998, Lisboa. Anais... Lisboa: Câmara Municipal de Lisboa/Pelouro do Desporto, 1998. p. 93-95.

CHIMOT, C. Repartition Sexuee des Postes a Responsabilite dans les Organisations Sportives. European Women Sport, 2004. Disponível em: <http://www.ews-online.org/files/doc/Conference-Paris/caroline_chimot_en.pdf $>$. Acesso em 12 Abr. 2009.

COSTA, M. E Mulher Pode Ser Gestora de Alguma Coisa?. Caderno de Estudos Ciência e Empresa, v. 4, n. 2, p. 1-14, set., 2007. Disponível em: <http://www.faete.edu.br/revista/E_MULHER_PODE_SER_GESTORA_DE_ALGUMA_COISA2.pdf $>$. Acesso em 12 nov. 2008 .

COUTO, A. O lado feminino do 25 de Abril. Jornalismo Porto Net, 26 abr. 2005. Disponível em: <http://jpn.c2com.up.pt/2005/04/26/o_lado_feminino_do_25_de_abril.html >. Acesso em 27 nov. 2008.

CRUZ, A. M. ONGS de mulheres: Caminho de participação e democracia? Revista ex-aequo, Vira Franca de Xira, n. 13, p.155-161, 2006.

CRUZ, I.; SILVA, P.; BOTELHO-GOMES, P. Deusas e Guerreiras: dos jogos olímpicos. Lisboa: Colecção Fio de Ariana, 2006.

FERNÁNDEZ, F. R.; VENTURA, K. E. Mujeres en los Órganos de Gobierno de las Organizaciones Deportivas Espanolas. Comisión Mujer y Deporte: Comité Olímpico Espanol, 2005. Disponível em: $<$ http://www.mujerydeporte.org/documentos/docs/Estudio.pdf $>$. Acesso em 25 jan. 2010.

FREITAS, S. Mulher: fonte e instrumento de poder. In: SIMÕES, A. (org.), Mulher \& Esporte: Mitos e verdades. São Paulo: Manole, 2003. p. 49-68. 
GOMES, E. Participação das Mulheres na Gestão do Esporte Brasileiro: Desafios e Perspectivas. Rio de Janeiro: Quartet Editora \& Comunicações, 2008.

INSTITUTE OF SPORT AND LEISURE POLICY. Woman, Leadership and the Olympic Movement Final Report. Leicestershire: Loughborough University, 2004. Disponível em: <http://www.olympic.org/Documents/Reports/EN/en_report_885.pdf>. Acesso em 17 fev. 2009.

INSTITUTO NACIONAL DE ESTATISTICA. Mulheres e Homens em Portugal nos Anos 90. Lisboa, 2002. Disponível em: $<$ http://www.ine.pt/xportal/xmain?xpid=INE\&xpgid=ine_genero_estudo\&menuBOUI=13707294\&ESTUDOSest boui $=106436 \&$ ESTU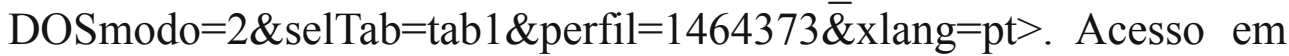 20 jan. 2009.

NEVES, M. Mulheres têm pouco acesso a cargos públicos no Brasil. Agência Câmara Notícias, 08 jul. 2007. Disponível em: $<$ http://www2.camara.gov.br/camaranoticias/noticias/99088.html $>$. Acesso em 17 nov. 2009.

OLIVEIRA, R.; POLIDORO, D.; SIMÕES, A. Perspectivas de vida e transição de carreira mulheres-atletas de Voleibol. In: SIMÕES, A. (Org.). Mulher \& Esporte: Mitos e verdades. São Paulo: Manole, 2003. p.177- 192.

PERISTA, H.; MAXIMIANO, S.; FREITAS, F. Família, género e trajectórias de vida: uma questão de (usos do) tempo. In: CONGRESSO PORTUGUÊS DE SOCIOLOGIA, 4., 2000, Coimbra. Atas... Coimbra: Universidade de Coimbra, 2000. Disponível em: $<$ http://www.aps.pt/cms/docs_prv/docs/DPR462dffeb8da19_1.PDF>. Acesso em 20 jan. 2008.

PFISTER, G.; RADTKE, S. Mulheres Tomando a Liderança ou mulheres tomando a liderança nas organizações esportivas alemãs. Movimento, Porto Alegre, v. 13, n. 02, p. 91-129, 2007.

PINHEIRO, M. A Mulher e o Desporto - Que Realidade? In: CONGRESSO A MULHER E O DESPORTO, 1998, Lisboa. Anais... Lisboa: Câmara Municipal de Lisboa/Pelouro do Desporto, 1998. p. 23-27. 
PORTUGAL. Constituição da República Portuguesa. Disponível em: <http://www.parlamento.pt/Legislacao/Paginas/ConstituicaoRepublicaPortuguesa.aspx>. Acesso em 13 fev. 2009.

QUIVY, R.; CAMPENHOUDT, L. V. Manual de Investigação em Ciências Sociais. 4. ed. Lisboa: Editora Gradiva, 2005.

SIMÕES, A. A mulher em busca de seus limites no esporte moderno. In: SIMÕES, A. (Org.). Mulher \& Esporte: Mitos e verdades. São Paulo: Manole, 2003. p. 1- 30.

TALBOT, M. Sem Limites: com excepção dos limites impostos pelos outros? O papel da educação no desenvolvimento do desporto para as mulheres. Revista ex-aequo, Porto, n. 4, p. 27-40, 2001.

TORRES, A. et al. Porque não se revoltam as mulheres? Resultados de uma pesquisa nacional sobre a divisão do trabalho entre os sexos. . In: CONGRESSO PORTUGUÊS DE SOCIOLOGIA, 4., 2000, Coimbra. Atas... Coimbra: Universidade de Coimbra, 2000. Disponível em: <http://www.aps.pt/cms/docs_prv/docs/DPR462dfe43b4acc_1.PDF>. Acesso em 12 fev. 2009.

TOURAINE, Alain. EI Mundo de Las Mujeres. Barcelona: Paidos Ibérica, 2007.

UNITED NATIONS. Office of the Special Adviser on Gender Issues and Advancement of Women (OSAGI). Gender Mainstreaming an Overview. Nova York: [s. n.] 2002. Disponível em: $<$ http://www.un.org/womenwatch/osagi/pdf/e65237.pdf $>$. Acesso em 27 abr. 2009.

Recebido em: 15/01/2013

Revisado em: 26/06/2013

Aprovado em: 06/09/2013

Endereço para correspondência

mjc@fade.up.pt

Maria José Carvalho

Faculdade de Desporto da Universidade do Porto

Praça Gomes Teixeira

4099-002 Porto

PORTUGAL

Pensar a Prática, Goiânia, v. 16, n. 4, p. 956-1270, out./dez. 2013 